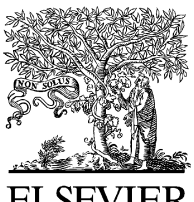

\title{
Modification of adenosine modulation of acetylcholine release in the hippocampus of aged rats ${ }^{\text {is }}$
}

\author{
Ricardo J. Rodrigues ${ }^{a}$, Paula M. Canas ${ }^{\text {a }}$, Luísa V. Lopes ${ }^{\text {b }}$, \\ Catarina R. Oliveira ${ }^{\text {a }}$, Rodrigo A. Cunha ${ }^{\mathrm{a}, *}$ \\ ${ }^{a}$ Center for Neuroscience of Coimbra, Faculty of Medicine, University of Coimbra, 3004-504 Coimbra, Portugal ${ }^{1}$ \\ ${ }^{\mathrm{b}}$ Institute of Pharmacology and Neurosciences, Institute of Molecular Medicine, University of Lisbon, Portugal
}

Received 28 September 2006; received in revised form 6 March 2007; accepted 23 March 2007

\begin{abstract}
Adenosine is a neuromodulator acting through inhibitory $A_{1}$ receptors $\left(A_{1} R s\right)$ and facilitatory $A_{2 A}$ Rs. Since $A_{2 A} R$ antagonists attenuate memory deficits in aged animals and memory deficits might involve a decreased cholinergic function, we investigated how aging affects the density and function of adenosine receptors in rat hippocampal cholinergic terminals. In young adult ( 2 months) rats, 64 and $36 \%$ of cholinergic terminals (immunopositive for vesicular $\mathrm{ACh}$ transporters) possessed $\mathrm{A}_{1} \mathrm{Rs}$ and $\mathrm{A}_{2 \mathrm{~A}}$ Rs, respectively. In aged ( 24 months) rats, the percentage of cholinergic terminals with $\mathrm{A}_{1}$ Rs was preserved, whereas that with $\mathrm{A}_{2 \mathrm{~A}}$ Rs was larger (49\%). In young adults adenosine only tonically inhibited ACh release through $A_{1} R s$, whereas in aged rats there was a greater $A_{1} R$-mediated inhibition and a simultaneous $A_{2 A} R$-mediated facilitation of $A C h$ release. Thus, the enhanced $A_{2 A} R$ density and facilitation compensates for the greater tonic $A_{1} R$ modulation, preserving the global adenosine modulation of $\mathrm{ACh}$ release in aged rats. Furthermore, since $\mathrm{A}_{2 \mathrm{~A}} \mathrm{R}$ antagonists inhibit ACh release, the beneficial effects of $\mathrm{A}_{2 \mathrm{~A}} \mathrm{R}$ antagonists on memory in aged rats might not result from ACh release modulation.
\end{abstract}

(C) 2007 Elsevier Inc. All rights reserved.

Keywords: Adenosine; Acetylcholine; Aging; Nerve terminals; Localization; Density

\section{Introduction}

Adenosine is a neuromodulator that acts through activation of inhibitory $A_{1}$ receptors $\left(A_{1} R s\right)$ and facilitatory $A_{2 A} R s$, which are mainly located in synapses (Fredholm et al., 2005). It was recently shown that $\mathrm{A}_{2 \mathrm{~A}} \mathrm{R}$ antagonists recover memory deficits in aged animals (Prediger et al., 2005) and in animal models of Alzheimer's disease (Dall'Igna et al., 2007).

\footnotetext{
is Disclosure: None of the authors has any actual or potential conflicts of interest including any financial, personal or other relationships with other people or organizations within 3 years of beginning the work submitted that could inappropriately influence (bias) our work. We also do not have contracts relating to this research through which ours or any other organization may stand to gain financially now or in the future. Our Institutions do not have a financial interest in this work.

* Corresponding author. Tel.: +351 239820190; fax: +351 239822776.

E-mail address: racunha@ci.uc.pt (R.A. Cunha).
}

Upon ageing, as well as upon chronic noxious brain conditions, adenosine modulation is modified with increased levels of adenosine, increased density and effects of $\mathrm{A}_{2 \mathrm{~A}}$ Rs and a decrease of $\mathrm{A}_{1} \mathrm{Rs}$ (Cunha et al., 2001; Lopes et al., 1999; reviewed in Cunha, 2005).

One hypothesis, still debatable (Bartus, 2000; Sarter and Bruno, 2004), to explain age-related memory deterioration is the cholinergic hypothesis, which is mainly based on the loss of basal forebrain cholinergic neurons on aging and the effect of anti-cholinergic drugs on learning and memory performance (reviewed in Bartus, 2000). Cholinergic dysfunction can affect memory by impacting on different cortical regions, namely in the hippocampus, as made evident by the ability of increasing hippocampal function by enhancing cholinergic transmission in individuals with memory deficits (Goekoop et al., 2006; Gron et al., 2006). Since adenosine can modulate the release of acetylcholine (ACh) in the hippocampus of young adult rats through the activation of both inhibitory 
$A_{1}$ and facilitatory $A_{2 A}$ receptors (Cunha et al., 1994), we now investigated if the beneficial effects afforded by $\mathrm{A}_{2 \mathrm{~A}}$ receptor antagonists in learning and memory abilities of aged rats might be related to a modified adenosine receptor setting and modulation of $\mathrm{ACh}$ release in the hippocampus of aged rats. Thus, we tested how aging affects the density of adenosine receptors in cholinergic terminals and the tonic adenosine modulation of acetylcholine release in the rat hippocampus.

\section{Methods}

Male Wistar rats, either young adults (2 months, 140$160 \mathrm{~g}$ ) or aged (24 months, 780-940 g) were obtained from Harlan Ibérica (Barcelona, Spain). They were handled according to the EU guidelines for use of experimental animals (86/609/EEC), the rats being anesthetized under halothane atmosphere before being sacrificed by decapitation.

\subsection{Immunocytochemical analysis in nerve terminals}

The double or triple labelling immunocytochemical analysis of hippocampal nerve terminals to quantify the localization of $A_{1}$ and $A_{2 A}$ receptors in cholinergic terminals was performed essentially as previously described (Rebola et al., 2005). Nerve terminals from the rat hippocampus were purified through a discontinuous Percoll gradient (see Rebola et al., 2005) and placed onto coverslips previously coated with poly-L-lysine, fixed with $4 \%$ paraformaldehyde for $15 \mathrm{~min}$ and washed twice with PBS medium $(140 \mathrm{mM}$ $\mathrm{NaCl}, 3 \mathrm{mM} \mathrm{KCl}, 20 \mathrm{mM} \mathrm{NaH} \mathrm{PO}_{4}, 15 \mathrm{mM} \mathrm{KH}_{2} \mathrm{PO}_{4}, \mathrm{pH}$ 7.4). The synaptosomes were permeabilized in PBS with $0.2 \%$ Triton $\mathrm{X}-100$ for $10 \mathrm{~min}$ and then blocked for $1 \mathrm{~h}$ in PBS with $3 \%$ bovine serum albumin (BSA) and 5\% normal rat serum. The synaptosomes were then washed twice with PBS and incubated with goat anti- $\mathrm{A}_{2 \mathrm{~A}}$ receptor (1:500, from Santa Cruz Biotechnology-Europe, Freelab, Lisbon, Portugal) and/or with rabbit anti-adenosine $\mathrm{A}_{1}$ receptor antibody (1:400, from Affinity Bioreagents, Golden, USA), together with guinea-pig anti-vesicular acetylcholine transporter (vAChT) antibody (1:500, from Chemicon, Hofheim, Germany) for $1 \mathrm{~h}$ at room temperature. The synaptosomes were then washed three times with PBS with 3\% BSA and incubated for $1 \mathrm{~h}$ at room temperature with AlexaFluor-488 (green) labelled donkey anti-goat IgG antibody (1:100), carefully washed with PBS and then incubated for $1 \mathrm{~h}$ at room temperature with AlexaFluor-598 (red) labelled goat antiguinea-pig $\operatorname{IgG}(1: 200)$ and AlexaFluor-350 (blue) labelled goat anti-rabbit (1:100) (all from Invitrogen, Eugene, USA), to avoid recognition of the goat anti-guinea-pig and goat anti-rabbit antibodies by the donkey anti-goat antibody. We confirmed that none of the secondary antibodies produced any signal in preparations to which the addition of the corresponding primary antibody was omitted. In particular, we confirmed that, in the absence of the goat anti- $\mathrm{A}_{2 \mathrm{~A}}$ receptor antibody, the addition to nerve terminals of the secondary donkey anti-goat antibody followed by the subsequent addition of the secondary goat anti-guinea-pig and anti-rabbit antibodies did not yield any signal. Most importantly, we confirmed that the individual signals in double-labelled fields are not enhanced over the signals under single-labelling conditions. After washing and mounting on slides with Prolong Antifade, the preparations were visualized in a Zeiss Axiovert 200 inverted fluorescence microscope equipped with a cooled CCD camera and analyzed with MetaFluor 4.0 software. Each coverslip (three to four per experiment) was analyzed by counting three different fields and in each field a minimum of 50 individualized elements. The values are presented as the percentage of the total number of cholinergic terminals (i.e. immunopositive for the vesicular acetylcholine transporter) that were labelled with $\mathrm{A}_{1}$ and/or $\mathrm{A}_{2 \mathrm{~A}}$ receptors and are displayed as mean \pm S.E.M. of $n$ experiments (i.e. in preparation obtained from different rats).

\subsection{Release of acetylcholine from hippocampal slices}

The release of $\left[{ }^{3} \mathrm{H}\right]$ acetylcholine $\left(\left[{ }^{3} \mathrm{H}\right] \mathrm{ACh}\right)$ from rat hippocampal slices was performed as previously described (Cunha et al., 1994). Briefly, slices were loaded with $\left[{ }^{3} \mathrm{H}\right]$ choline $(30 \mu \mathrm{Ci} / \mathrm{ml}, 0.3 \mu \mathrm{M})$ for $30 \mathrm{~min}$, washed, placed in 100- $\mu 1$ Perspex chambers, and superfused with oxygenated Krebs solution containing $10 \mu \mathrm{M}$ hemicholinium- 3 at $30^{\circ} \mathrm{C}$ with a flow rate of $0.6 \mathrm{ml} / \mathrm{min}$. Slices were stimulated twice (S1 and S2) at 6 and 36 min with supra-maximal monopolar square-wave pulses with a duration of $3 \mathrm{~ms}$ and an amplitude of $40 \mathrm{~V}$, delivered with a frequency of $5 \mathrm{~Hz}$ for a period of $2 \mathrm{~min}$ (600 pulses), through platinum electrodes. Tested drugs (DPCPX, ZM241385 or adenosine deaminase) were added to the superfusion medium 15 min before $\mathrm{S} 2$ and remained in the bath up to the end of the experiment. The effect of drugs was estimated by comparison of tritium release in control chambers (no added drugs) and test chamber by quantifying the ratio of the amount of tritium released in S2 (eventually in the presence of tested drugs) and S1 (internal control). We used supra-maximal but selective concentrations of the $\mathrm{A}_{1}$ receptor antagonist DPCPX $(50 \mathrm{nM})$ and of the $\mathrm{A}_{2 \mathrm{~A}}$ receptor antagonist ZM241385 (50 $\mathrm{nM})$, to determine the effect of endogenous adenosine on each receptor (see Lopes et al., 1999; Rebola et al., 2005). To determine the effect of the removal of extracellular adenosine, we tested the effect of $2 \mathrm{U} / \mathrm{ml}$ of adenosine deaminase, as previously done (Cunha et al., 2001). At the end of the release experiments, $5 \mathrm{ml}$ of scintillation cocktail (Scintran T) was added to a $500 \mu \mathrm{l}$ aliquot of each eluent fraction and to $100 \mu \mathrm{l}$ of the homogenized slices (sonicated in $500 \mu \mathrm{l}$ of $3 \mathrm{M}$ perchloric acid and $2 \%$ Triton X-100). The fractional release was expressed in terms of the percentage of total radioactivity present in the tissue at the time of sample collection. The release of tritium evoked by each period of electrical stimulation, i.e. the 
evoked release (expressed as fractional release), was calculated by integration of the area of the peak upon subtraction of the estimated basal tritium outflow from the total outflow due to electrical stimulation. The evoked release of tritium under these conditions is $\mathrm{Ca}^{2+}$ - and tetrodotoxinsensitive and is mostly constituted by $\left[{ }^{3} \mathrm{H}\right] \mathrm{ACh}$ (Cunha et al., 1994).

\subsection{Statistics}

Values are mean \pm S.E.M. of $n$ experiments. The significance of the effects of tested drugs was calculated by the paired Student's $t$-test, and the effect of a drug between age groups by the two-tailed Mann-Whitney $U$-test. $P<0.05$ was considered to represent a significant difference.

\section{Results and discussion}

We have previously shown that the release of acetylcholine (ACh) from hippocampal preparations is under the dual control of inhibitory $A_{1}$ and facilitatory $A_{2} A$ receptors $\left(A_{1} R s\right.$ and $A_{2 A}$ Rs) (Cunha et al., 1994; Lopes et al., 1999). However, it is not clear if different cholinergic terminals in the hippocampus are endowed with each of the receptors or whether the two adenosine receptor subtypes are located in the same cholinergic terminals. To answer this question, we carried out double and triple immunocytochemical studies to detect $\mathrm{A}_{1} \mathrm{Rs}$ and $\mathrm{A}_{2 \mathrm{~A}} \mathrm{Rs}$ in hippocampal cholinergic nerve terminals, identified as immunopositive for vesicular acetylcholine transporters (Fig. 1). In young adult rats (2 months old), $64.4 \pm 3.1 \%$ of cholinergic terminals (immunopositive
(A)
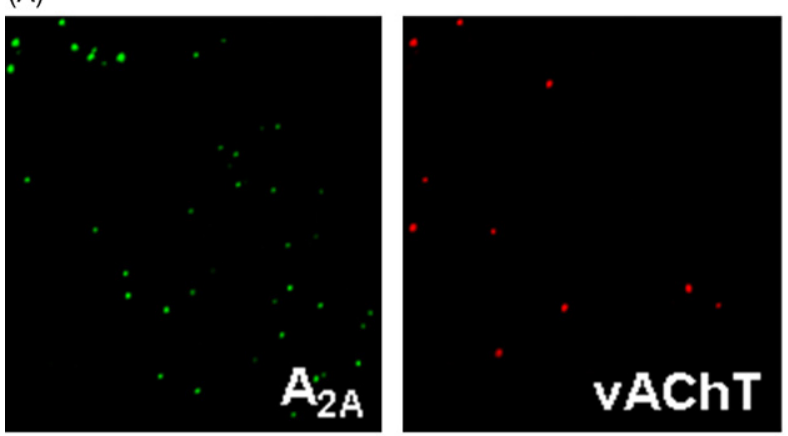

(B)

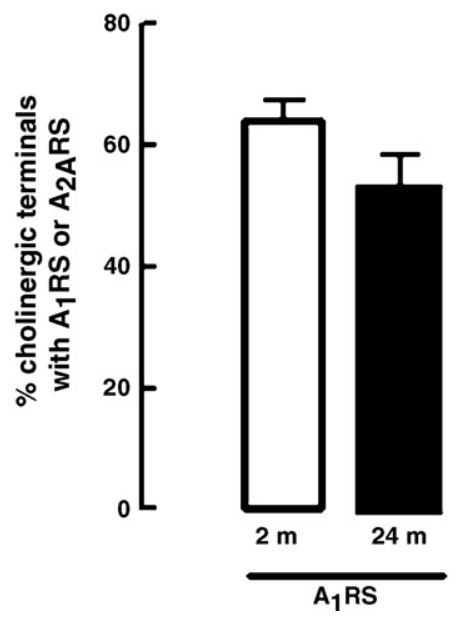

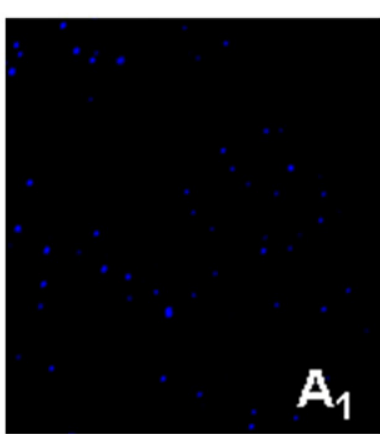

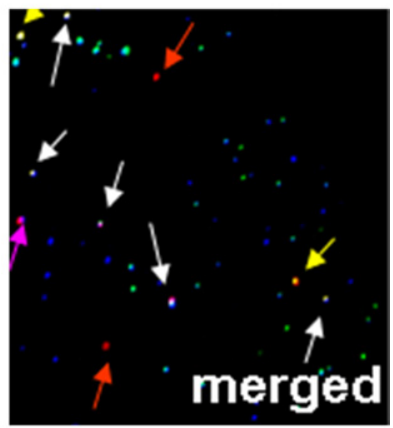

(C)

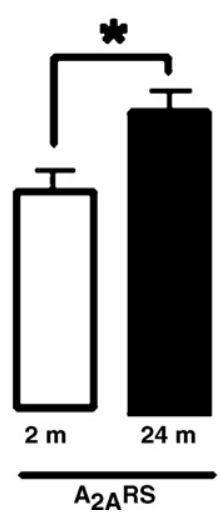

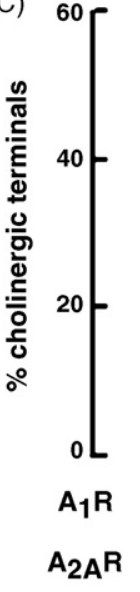

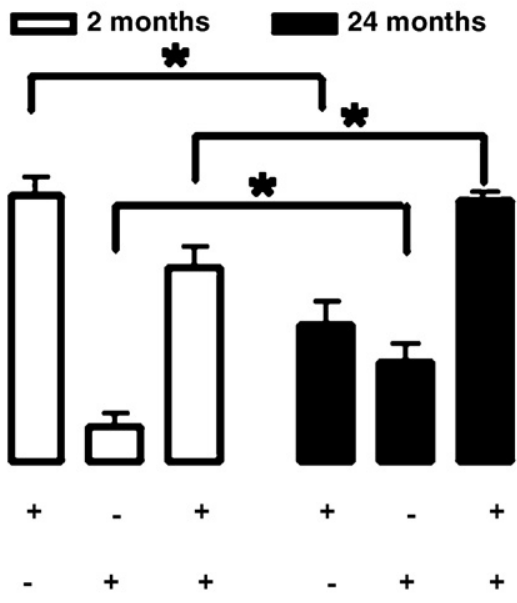

Fig. 1. Co-localization of adenosine $A_{1}$ and $A_{2 A}$ receptors in rat hippocampal cholinergic nerve terminals. (A) Shows the immunocytochemical identification of $A_{2 A}$ receptors (first panel from left), vesicular acetylcholine transporters (second from left), $A_{1}$ receptors (third from left) in rat hippocampal nerve terminals from aged rats and the merged image (fourth from left) showing cholinergic terminals without adenosine receptors (red arrows), with only $\mathrm{A}_{1}$ receptors (violet arrows), with only $\mathrm{A}_{2 \mathrm{~A}}$ receptors (yellow arrows) and with both $\mathrm{A}_{1}$ and $\mathrm{A}_{2 \mathrm{~A}}$ receptors (white arrows). These pictures are amplifications representative of larger photographed fields with at least three different fields per coverslip and three to four coverslips per experiment. For instance, in this experiment we identified a total number of 74 elements immunopositive for vAChTs, out of which 16 were immunopositive only for $\mathrm{A}_{1}$ receptors, 7 immunopositive only for $\mathrm{A}_{2 \mathrm{~A}}$ receptors and 28 were immunopositive for both $\mathrm{A}_{1}$ and $\mathrm{A}_{2 \mathrm{~A}}$ receptors. This experiment was repeated using different synaptosomal preparations from different $(n=7)$ aged (24 months, ' $24 \mathrm{~m}$ ') rats. (B) Displays the average percentage of rat hippocampal cholinergic terminals (i.e. synaptosomes immunopositive for vAChTs) endowed with either $\mathrm{A}_{1}$ or $\mathrm{A}_{2 \mathrm{~A}}$ receptors in young adult ( 2 months, ' 2 m', open bars, $\left.n=5\right)$ and aged rats (filled bars, $\left.n=7\right)$. (C) Compares the average percentage of rat hippocampal cholinergic terminals endowed with only $\mathrm{A}_{1}$ or only $\mathrm{A}_{2 \mathrm{~A}}$ or both $\mathrm{A}_{1}$ and $\mathrm{A}_{2 \mathrm{~A}}$ receptors in young adult (open bars, $n=5$ ) and aged rats (filled bars, $n=7$ ). The data in the histograms are mean \pm S.E.M. ${ }^{*} P<0.05$. (For interpretation of the references to colour in this figure legend, the reader is referred to the web version of the article.) 
for vesicular $\mathrm{ACh}$ transporters) were endowed with $\mathrm{A}_{1} \mathrm{Rs}$ and $35.9 \pm 3.4 \%$ possessed $\mathrm{A}_{2 \mathrm{~A}} \mathrm{Rs}(n=5)$. The two receptors were co-located in $26.0 \pm 2.6 \%$ of cholinergic terminals, whereas $35.8 \pm 2.5 \%$ were endowed only with $\mathrm{A}_{1}$ Rs and virtually none $(4.0 \pm 1.9 \%)$ of the cholinergic terminals were endowed with only $\mathrm{A}_{2 \mathrm{~A}} \mathrm{Rs}(n=4)$. This shows that there is an asymmetric distribution of adenosine receptors in the hippocampus of young adult rats, such that $1 / 3$ of cholinergic terminals only has $\mathrm{A}_{1} \mathrm{Rs}, 1 / 3$ has both $\mathrm{A}_{1}$ Rs and $\mathrm{A}_{2 \mathrm{~A}} \mathrm{Rs}$ and $1 / 3$ apparently lacks adenosine receptors. This agrees with the relative amplitude of the modulatory effects operated by $\mathrm{A}_{1}$ Rs and $\mathrm{A}_{2 \mathrm{~A}}$ Rs in the control of $\mathrm{ACh}$ release in hippocampal preparations from young adult rats (Cunha et al., 1994; Lopes et al., 1999). There is a predominant $\mathrm{A}_{1} \mathrm{R}$-mediated inhibition of ACh release that causes a maximal inhibition of near 50\% and a discrete $\mathrm{A}_{2 \mathrm{~A}} \mathrm{R}$-mediated facilitation (Cunha et al., 1994; Jin and Fredholm, 1997; Lopes et al., 1999).

We then carried out the same double and triple immunocytochemical labelling in aged rats ( 24 months old). We found that the percentage of cholinergic terminals with $\mathrm{A}_{1} \mathrm{Rs}$ was preserved $(53.3 \pm 5.2 \%, n=7, P>0.05)$ compared to young adult rats. In contrast, the percentage of cholinergic terminals with $\mathrm{A}_{2 \mathrm{~A}} \mathrm{Rs}$ was larger $(49.0 \pm 3.4 \%, n=7, P<0.05)$ than in young adult rats. Finally, we found that the percentage of cholinergic terminals simultaneously endowed with $\mathrm{A}_{1}$ Rs and $\mathrm{A}_{2 \mathrm{~A}} \mathrm{Rs}(35.7 \pm 1.3 \%, n=5)$ was larger $(P<0.05)$ than in young adult rats, and there was a lower proportion of cholinergic terminals endowed only with $\mathrm{A}_{1} \mathrm{Rs}(18.3 \pm 2.9 \%$, $n=5, P<0.05$ ) and a greater proportion of cholinergic terminals endowed only with $\mathrm{A}_{2 \mathrm{~A}} \mathrm{Rs}(13.4 \pm 2.1 \%, n=5, P<0.05)$ compared to young adult rats. Thus, there is a re-distribution of adenosine receptors in cholinergic terminals of aged rats and the major modification is a greater abundance of $\mathrm{A}_{2 \mathrm{~A}} \mathrm{Rs}$ in cholinergic terminals. There is now a significant proportion of cholinergic terminals with only $\mathrm{A}_{2 \mathrm{~A}}$ Rs and a larger percentage of cholinergic terminals with both $\mathrm{A}_{1}$ Rs and $\mathrm{A}_{2 \mathrm{~A}}$ Rs. In accordance with this greater abundance of $\mathrm{A}_{2 \mathrm{~A}}$ Rs in hippocampal cholinergic terminals of aged rats, the activation of $\mathrm{A}_{2 \mathrm{~A}} \mathrm{Rs}$ causes a larger facilitation of ACh release in hippocampal preparations from aged compared to young adult rats (Lopes et al., 1999).

The density of the two receptors and the amplitude of their modulation effects upon activation with exogenously added agonists provide evidence of changes in the relative importance of the two receptors but does not tell us about the intrinsic efficiency of these two receptors with opposite roles. In fact, this depends on the levels of endogenous extracellular adenosine tonically activating these two receptors in cholinergic terminals. Previous studies have shown that the levels of endogenous extracellular adenosine are larger in hippocampal preparations from aged compared to young adult rats (Cunha et al., 2001). When investigating glutamatergic synaptic transmission, where there is also a greater effect of $A_{2 A} R$ agonists and a lower effect of $A_{1} R$ agonists in aged rats, we found that the greater levels of extracellular adenosine cause a greater tonic $\mathrm{A}_{1} \mathrm{R}$-mediated inhibition in aged rats (Sebastião et al., 2000), while there is no evidence of a tonic $\mathrm{A}_{2 \mathrm{~A}} \mathrm{R}$-mediated facilitation (Rebola et al., 2003). Thus, we now compared the effect of endogenous extracellular adenosine tonically modulating the release of ACh in young adult and aged rats. The blockade of $A_{1}$ Rs, using the $A_{1} R$-selective antagonist DPCPX $(50 \mathrm{nM})$, enhanced $(17.2 \pm 3.8 \%, n=5)$ ACh release in young rats (see Cunha et al., 1994) and this tonic $\mathrm{A}_{1} \mathrm{R}$-mediated inhibition was greater in aged rats $(35.2 \pm 4.0 \%, n=6, P<0.05)$. There was also a more pronounced role of adenosine tonically facilitating ACh release in aged rats since the blockade of $\mathrm{A}_{2 \mathrm{~A}} \mathrm{Rs}$ with ZM241385 (50 nM) decreased ACh release by $11.5 \pm 1.3 \%(n=7)$ in aged rats and was devoid of effects $(-4.0 \pm 1.4 \%, n=6)$ in young adult rats. This indicates that the lower levels of adenosine in young adults are only tonically inhibiting $\mathrm{ACh}$ release through $\mathrm{A}_{1} \mathrm{Rs}$, whereas the greater levels of adenosine in aged rats (Cunha et al., 2001) caused a greater $\mathrm{A}_{1} \mathrm{R}$-mediated inhibition and a simultaneous $\mathrm{A}_{2 \mathrm{~A}} \mathrm{R}$-mediated facilitation of ACh release. Accordingly, removing endogenous extracellular adenosine with $2 \mathrm{U} / \mathrm{ml}$ adenosine deaminase (converts adenosine into its centrally inactive metabolite, inosine) caused a similar facilitation of ACh release in young adult $(15.3 \pm 2.8 \%, n=6)$ and aged rats $(19.3 \pm 1.1 \%, n=7, P>0.05)$. These results indicate that there is an enhanced $\mathrm{A}_{2 \mathrm{~A}} \mathrm{R}$ density and facilitation of $\mathrm{ACh}$ release to compensate for the greater tonic $A_{1} R$ modulation of ACh release, preserving the global adenosine modulation of ACh release in aged rats (Fig. 2).

This conclusion is of particular relevance to understand the mechanisms operated by $\mathrm{A}_{2 \mathrm{~A}}$ Rs to selectively enhance mnemonic function in aged animals (Prediger et al., 2005).

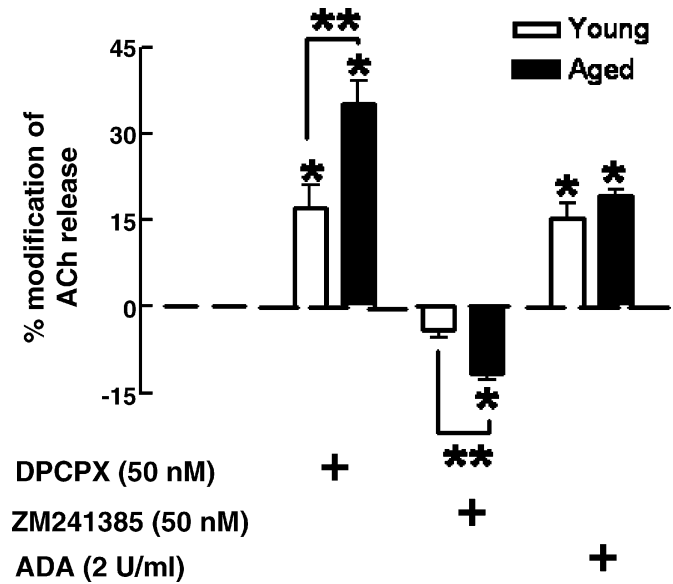

Fig. 2. Comparison of the tonic modulation by endogenous adenosine of $\left[{ }^{3} \mathrm{H}\right]$ acetylcholine $\left(\left[{ }^{3} \mathrm{H}\right] \mathrm{ACh}\right)$ release from rat hippocampal slices of young adult ( 2 months old, open bars) and aged rats ( 24 months old, filled bars). The effect of the selective $\mathrm{A}_{1}$ receptor antagonist, DPCPX $(50 \mathrm{nM})$, of the selective $\mathrm{A}_{2 \mathrm{~A}}$ receptor antagonist, ZM241385 $(50 \mathrm{nM})$ and of adenosine deaminase $(2 \mathrm{U} / \mathrm{ml}$, which converts adenosine into its inactive metabolite inosine) was estimated by following the evoked $\left[{ }^{3} \mathrm{H}\right] \mathrm{ACh}$ release upon fieldelectrically stimulation $(40 \mathrm{~V}, 3 \mathrm{~ms}, 5 \mathrm{~Hz}, 2 \mathrm{~min})$ of the slices. Values are means \pm S.E.M. of four to seven experiments. ${ }^{*} P<0.05 \%$ vs. $0 \%{ }^{* *} P<0.05$ between the two age group. 
One possible mechanism could be the control of ACh since there is a hypofunction of the limbic cholinergic system upon aging, which is considered a possible cause of cognitive deterioration with aging (Bartus, 2000; Fischer et al., 1992; Sarter and Bruno, 2004). However, we now observed that there is a greater tonic $\mathrm{A}_{2 \mathrm{~A}} \mathrm{R}$-mediated facilitation of $\mathrm{ACh}$ release in hippocampal slices from aged rats and that $\mathrm{A}_{2 \mathrm{~A}} \mathrm{R}$ antagonists decrease ACh release in aged rats. Based on the hypothesis of cholinergic hypofunction, this is precisely the opposite of what would be expected to understand the beneficial effect of $\mathrm{A}_{2 \mathrm{~A}} \mathrm{R}$ antagonists on memory performance in aged rats (i.e. drugs enhancing memory were expected to increase $\mathrm{ACh}$ release). Thus, the present results indicate that the benefits afforded by $\mathrm{A}_{2 \mathrm{~A}} \mathrm{R}$ antagonists on memory performance in aged rats are likely not related to the control of the cholinergic system. Further studies are required to explore if the beneficial effects of $\mathrm{A}_{2 \mathrm{~A}} \mathrm{R}$ antagonists on memory performance in aged rats may instead involve the control of GABA release, NMDA receptors, astrocytic function or neuroinflammation (reviewed in Cunha, 2005; Fredholm et al., 2005).

\section{Acknowledgments}

Supported by Fundação para a Ciência e Tecnologia (POCI/SAU-FCF/59215/2004) and by a Pfizer Award from the Portuguese Society of Neuroscience.

\section{References}

Bartus, R.T., 2000. On neurodegenerative diseases, models, and treatment strategies: lessons learned and lessons forgotten a generation following the cholinergic hypothesis. Exp. Neurol. 163, 495-529.

Cunha, R.A., 2005. Neuroprotection by adenosine in the brain: from $\mathrm{A}_{1}$ receptor activation to $A_{2 A}$ receptor blockade. Purinergic Signal 1, 111-134.

Cunha, R.A., Milusheva, E., Vizi, E.S., Ribeiro, J.A., Sebastião, A.M., 1994. Excitatory and inhibitory effects of $\mathrm{A}_{1}$ and $\mathrm{A}_{2 \mathrm{~A}}$ adenosine receptor activation on the electrically evoked $\left[{ }^{3} \mathrm{H}\right]$ acetylcholine release from different areas of the rat hippocampus. J. Neurochem. 63, 207-214.
Cunha, R.A., Almeida, T., Ribeiro, J.A., 2001. Parallel modification of adenosine extracellular metabolism and modulatory action in the hippocampus of aged rats. J. Neurochem. 76, 372-382.

Dall'Igna, O.P., Fett, P., Gomes, M.W., Souza, D.O., Cunha, R.A., Lara, D.R., 2007. Caffeine and adenosine $A_{2 A}$ receptor antagonists prevent $\beta$ amyloid (25-35)-induced cognitive deficits in mice. Exp. Neurol. 203, 241-245.

Fischer, W., Chen, K.S., Gage, F.H., Bjorklund, A., 1992. Progressive decline in spatial learning and integrity of forebrain cholinergic neurons in rats during aging. Neurobiol. Aging 13, 9-23.

Fredholm, B.B., Chen, J.F., Cunha, R.A., Svenningsson, P., Vaugeois, J.M., 2005. Adenosine and brain function. Int. Rev. Neurobiol. 63, 191270

Goekoop, R., Scheltens, P., Barkhoh, F., Rombouts, S.A.R.B., 2006. Cholinergic challenge in Alzheimer patients and mild cognitive impairment differently affects hippocampal activation-a pharmacological fMRI study. Brain 129, 141-157.

Gron, G., Brandenburg, I., Wunderlich, A.P., Riepe, M.W., 2006. Inhibition of hippocampal function in mild cognitive impairment: targeting the cholinergic hypothesis. Neurobiol. Aging 27, 78-87.

Jin, S., Fredholm, B.B., 1997. Adenosine $A_{2 A}$ receptor stimulation increases release of acetylcholine from rat hippocampus but not striatum, and does not affect catecholamine release. Naunyn Schmiedeberg's Arch. Pharmacol. 355, 48-56.

Lopes, L.V., Cunha, R.A., Ribeiro, J.A., 1999. Increase in the number, G protein coupling, and efficiency of facilitatory adenosine $\mathrm{A}_{2 \mathrm{~A}}$ receptors in the limbic cortex, but not striatum, of aged rats. J. Neurochem. 73, 1733-1738.

Prediger, R.D., Batista, L.C., Takahashi, R.N., 2005. Caffeine reverses age-related deficits in olfactory discrimination and social recognition memory in rats. Involvement of adenosine $\mathrm{A}_{1}$ and $\mathrm{A}_{2 \mathrm{~A}}$ receptors. Neurobiol. Aging 26, 957-964.

Rebola, N., Sebastião, A.M., de Mendonça, A., Oliveira, C.R., Ribeiro, J.A., Cunha, R.A., 2003. Enhanced adenosine $\mathrm{A}_{2 \mathrm{~A}}$ receptor facilitation of synaptic transmission in the hippocampus of aged rats. J. Neurophysiol. 90, 1295-1303.

Rebola, N., Rodrigues, R.J., Lopes, L.V., Richardson, P.J., Oliveira, C.R., Cunha, R.A., 2005. Adenosine $\mathrm{A}_{1}$ and $\mathrm{A}_{2 \mathrm{~A}}$ receptors are co-expressed in pyramidal neurons and co-localized in glutamatergic nerve terminals of the rat hippocampus. Neuroscience 133, 79-83.

Sarter, M., Bruno, J.P., 2004. Developmental origins of the age-related decline in cortical cholinergic function and associated cognitive abilities. Neurobiol. Aging 25, 1127-1139.

Sebastião, A.M., Cunha, R.A., de Mendonça, A., Ribeiro, J.A., 2000. Modification of adenosine modulation of synaptic transmission in the hippocampus of aged rats. Br. J. Pharmacol. 131, 1629-1634. 